\title{
Crédito de imposto sobre produtos industrializados e insumos com alíquota zero
}

\author{
Cristiano Brito Lins Costa ${ }^{1}$ \\ André Toledo Rodriguez ${ }^{2}$
}

\begin{abstract}
Resumo
Analisou-se a questão da não-cumulatividade na incidência do imposto sobre produtos industrializados, o que decorre de norma constitucional e ainda se tal característica sofre limitações. Definiu-se extrafiscalidade, função importante para entender a questão da alíquota zero, prática esta que se dá em virtude do princípio da seletividade, 0 qual se mostrou como importante instrumento da extrafiscalidade. Traçou-se diferenciação sobre o que seriam produtos com isenção tributária e aqueles sujeitos a alíquota zero. Estudou-se a problemática do direito, ou não, de crédito de IPI em decorrência da aquisição de insumos sujeitos a alíquota, inclusive mostrando posições divergentes da doutrina nacional. Por fim, analisou-se o recente posicionamento do Supremo Tribunal Federal, em virtude de decisão proferida no início do ano, e ainda, quais seriam os efeitos da referida decisão.
\end{abstract}

Palavras-Chave: Não-cumulatividade; Extrafiscalidade; Princípio da seletividade; Crédito tributário; Isenção; Alíquota zero.

\section{Introdução}

0 imposto sobre produtos industrializados tem previsão constitucional da nãocumulatividade, inciso II, $\S 3^{\circ}$, art. 153 da CF. Diante de tal previsão, os industriais que compram insumos sob os quais já houve a incidência do IPI, têm o direito ao abatimento do valor a ser pago de IPI em seu produto final, correspondente ao IPI que já incidiu no insumo.

Ressalta-se que o estudo do IPI é de grande relevância, afinal é o imposto federal de segunda maior arrecadação, fincando atrás somente do imposto de renda, assim pode-se imaginar o quão vultosos são os valores em arrecadação quando se está a tratar de tal imposto.

Em decorrência do citado creditamento surgiu a discussão se ele se aplicaria, ou não, aos insumos utilizados no ciclo produtivo de determinado produto, que em razão do

\footnotetext{
${ }^{1}$ Acadêmico do 50 ano matutino do curso de Direito da Universidade Estadual de Londrina.

${ }^{2}$ Acadêmico do 5o ano matutino do curso de Direito da Universidade Estadual de Londrina.
} 
princípio da seletividade (inciso I, $\S 3^{\circ}$, art. 153 da CF) recebem alíquotas zero ou não são tributados.

Tal temática era amplamente abordada pela doutrina e em recente julgado (de 2007) o Supremo Tribunal Federal decidiu a problemática ao julgar dois Recursos Extraordinários.

\section{Da não-cumulatividade}

Este princípio aplica-se no caso do IPI em razão do inciso II, $\S 3^{\circ}$ do art. 153 da CF, 0 qual diz que "será não-cumulativo, compensando-se o que for devido em cada operação com o montante cobrado nas anteriores".

A citada determinação constitucional tem por escopo evitar o chamado "efeito cascata", e nas palavras do professor Hugo de Brito (2003, p. 495),

entende-se por não-cumulatividade a qualidade do imposto, o princípio segundo 0 qual em cada operação o contribuinte deduz 0 valor do imposto correspondente à saída dos produtos o valor que incidiu na operação anterior, de sorte que reste tributado somente $o$ valor acrescido. Em outras palavras, do valor do imposto que incide na saída dos produtos deduz-se o valor que incidiu nas operações anteriores sobre os respectivos produtos.

Assim a não-cumulatividade, conforme obra de David Torres, significa que 0 imposto "se compensa de operação em operação, subtraindo-se do total devido, em cada operação, o montante cobrado nas anteriores”(2003, p. 173).

0 Decreto n. 4.544 de 2002 traz a regulamentação do IPI e trata da nãocumulatividade em seu art. 163 dizendo:

A não-cumulatividade do imposto é efetivada pelo sistema de crédito, atribuído ao contribuinte, do imposto relativo a produtos entrados no seu estabelecimento, para ser abatido do que for devido pelos produtos dele saídos, num mesmo período, conforme estabelecido neste Capítulo (Lei №. 5.172, de 1966, art. 49).

Para Bottallo "a não-cumulatividade é técnica que se volta contra a União, na medida em que cada incidência do imposto determina, inexoravelmente, o surgimento de uma relação de crédito, em favor dos contribuintes"(2002, p. 44). 
Desta forma nota-se que a vedação da cumulatividade em caso de incidência do IPI consiste em abater do preço final do produto industrializado o valor correspondente ao IPI já pago em decorrência de anterior negociação de produto também industrializado, o qual foi utilizado como insumo daquele.

\section{Extrafiscalidade}

Antes de analisarmos a questão do princípio da seletividade, é de grande importância conceituar-se a 'extrafiscalidade'.

Para Paulo de Barros "consiste na forma de manejar elementos jurídicos utilizados na configuração dos tributos, perseguindo objetivos alheios aos meramente arrecadatórios (...)" $)^{\prime \prime}(2007$, p. 245).

O citado doutrinador ainda toma o próprio caso do IPI para exemplificar a extrafiscalidade, dizendo que "quanto ao IPI, a própria Constituição prescreve que suas

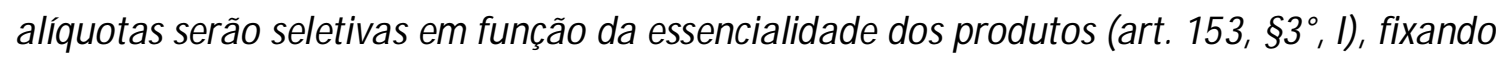
um critério que leva o legislador ordinário a estabelecer percentuais mais elevados para os produtos supérfluos"(2007, p. 245).

Elali, de forma simples demonstra a natureza extrafiscal do IPI, pois para o imposto "além de servir para a arrecadação tributária federal, serve de instrumento de controle e intervenção de setores da economia nacional"(2004, p. 78).

Por sua vez, Bottallo cita em sua obra o ensinamento de Modesto Carvalhosa, para quem extrafiscalidade é o "emprego do instrumento tributário com objetivos não fiscais, mas econômicos, ou seja, para finalidades não financeiras, mas regula tórias dos comportamentos sociais em matéria econômica, social e política"(1969, p. 90).

A extrafiscalidade será a utilização do imposto, no caso do IPI pela União, para fins não puramente arrecadatórios, podendo servir de incentivo a setores da economia ou até mesmo como forma de incentivar políticas de governo.

Da seletividade

Este princípio integrante da figura do IPI erige do art. $153, \S 3^{\circ} \mathrm{em}$ seu inciso I, "será seletivo, em função da essencialidade do produto". 
Sobre a seletividade em função da essencialidade David Torres traz em sua obra que:

Estamos diante de um tributo que terá suas alíquotas ponderadas de acordo com o grau de essencialidade do produto. O leite em pó, por exemplo, é um produto industrializado muito mais essencial que o cigarro e por essa razão sai alíquota é bem menor. (2003, p. 173)

Ricardo Lobo exprime que "seletividade em função da essencialidade é o único critério para a incidência do IPI e significa que o tributo recai sobre bens na razão inversa de sua necessidade para o consumo popular e na razão direta de sua superfluidade"(1994, p. 95).

Em virtude de tal característica o IPI é utilizado como 'instrumento de ordenação político-econômica', pois irá favorecer operações que o governo repute necessárias e podendo também dificultar, por meio do aumento da alíquota, a prática de operações que vão de encontro ao interesse coletivo, conforme ensina Bottallo (2002, p. 62).

\section{Diferenças de isenção e alíquota zero}

Seguindo as lições do professor Paulo de Barros Carvalho, tem-se que as isenções são normas introduzidas no ordenamento com o fim de mitigar a abrangência da regramatriz de incidência tributária, tal norma poderá incidir sobre um ou mais critérios da 'norma-padrão'.

O citado doutrinador ainda explica o fenômeno como:

0 encontro de duas normas jurídicas, sendo uma a regra-matriz de incidência tributária e outra a regra de isenção, com seu caráter supressor da área de abrangência de qualquer dos critérios da hipótese ou da conseqüência da primeira (regra-matriz). (2007, p.505)

Desta forma a isenção é instituída em virtude de lei ordinária ou complementar, conforme aludido acima, não se trata de uma forma de exclusão de crédito, pois na realidade 0 crédito não se constitui.

Por sua vez a questão da 'alíquota zero' ou do produto 'não-tributado' definitivamente não implica na ausência do evento tributário, na realidade, o que estará 
ausente é a medida para cálculo do dever tributário, ou seja, o critério quantitativo da relação jurídica tributária.

A redução da alíquota para zero não se dá em virtude de lei, podendo ser por meio de decreto a critério do Poder Executivo, conforme expressa previsão constitucional:

Art. $153-\S 1^{\circ}$ É facultado ao Poder Executivo, atendidas às condições e os limites previstos em lei, alterar as alíquotas dos impostos enumerados nos incisos I, II, IV e $\mathrm{V}$.

Nos termos da obra de David Torres:

Trata-se de uma peculiaridade do imposto e que facilita a sua utilização como instrumento de controle de mercado, incentivando-se ou não a produção de determinado bem. (2003, p. 174)

Nestes termos tem-se que o poder de reduzir a alíquota de determinados produtos

é uma discricionariedade atribuída ao Executivo, que em decorrência do princípio da seletividade, adote uma tributação com fins de extrafiscalidade.

Assim pode-se aumentar, ou diminuir, a alíquota de determinado produto conforme a sua relevância social, nestes termos pode-se reduzir a zero a alíquota ou até mesmo não instituir alíquota, o que tem o mesmo efeito.

Bottallo traz em sua obra entendimento no sentido de que a utilização da chamada alíquota zero seria uma isenção, pela redução da alíquota do tributo a zero, impossibilitando o surgimento de obrigações tributárias. E ainda destaca que a redução da alíquota a zero seria o menos que aniquilar o critério quantitativo, pois qualquer que seja a base de cálculo não subsistiria objeto da prestação.

\section{Do crédito decorrente de insumos com alíquota zero}

Para Bottallo o direito ao creditamento é devido, pois o contrário implica em anular por completo o efeito da norma incentivadora, explicando tal conseqüência da seguinte forma:

[...] 0 adquirente de insumos isentos ou sujeitos a alíquota zero, conquanto viesse a apagar preço aparentemente menor por estes insumos, acabaria suportando cargo tributária superior (em virtude de não poder creditar-se), restando anulado, por completo, o efeito buscado pela norma liberatória. $(2002$, p. 50) 
Para o citado autor tal direito decorreria do próprio art. $153, \S 3^{\circ}$, inciso II da CF, pois tal norma não trouxe qualquer tipo de ressalva quanto ao que seriam as 'operações anteriores', diferentemente do acontece no caso do ICM S, onde a Carta M agna determina a vedação expressa, conforme art. $155, \S 2^{\circ}$, inciso II:

A isenção ou não-incidência, salvo determinação em contrário da legislação: a) não implicará crédito para compensação com o montante devida nas operações ou prestações seguintes;

0 doutrinador ainda fortalece sua tese com a obra de Baleeiro, onde ensina que "o princípio da não-cumulatividade do IPI não sofre nenhuma limitação ou exceção Constitucional" (2003, p. 353).

O mesmo entendimento de Bottallo é compartilhado pelo professor Kiyoshi Harada, pois para ele o princípio da não-cumulatividade do IPI não deve sofrer qualquer limitação, justificando:

É que este imposto não se submete ao princípio da legalidade tributária no que tange à alteração de alíquotas (art. 153, § 1이, IV da CF). Em princípio, o Chefe do Poder Executivo poderá obter idêntico resultado de uma isenção, sempre dependente de lei, por meio de um decreto reduzindo a alíquota do IPI a ZERO. (2007, p. 01)

Diante das lições expostas pode-se concluir que limitar a aplicação do princípio da não-cumulatividade para o IPI só poderia se dar pela Constituição Federal, conforme ocorre com o ICM (S), ou seja, qualquer outra limitação estará eivada de inconstitucionalidade.

É importante ser destacado que também há na doutrina brasileira quem defenda a tese contrária ao creditamento na situação sob análise, que é o exemplo do professor Hugo de Brito Machado.

Para esse doutrinador, o direito ao creditamento é devido só na situação dos insumos isentos e não no caso daqueles sujeitos a alíquota zero ou não tributados, para isto se deve para preservar a eficácia da norma que concede a isenção, pois esta teria por base questões relevantes como estimular o desenvolvimento de determinada região. Por sua vez os produtos com alíquotas zero, pois para ele o princípio da seletividade só é cumprido se "ônus do IPI sobre cada produto seja o efetivamente resultante da aplicação da alíquota respectiva"(2007, p. 01). 
O mesmo jurista ainda afirma que “(...) garantir o direito ao crédito na aquisição de produtos não tributados, ou com alíquota zero, é conceder um verdadeiro prêmio aos industriais, que a tanto não têm direito, seja em face das leis ou em face dos princípios constitucionais."(2007, p. 01).

\section{Da decisão do Supremo Tribunal Federal}

A presente problemática chegou até a suprema corte nacional, a qual proferiu decisão em dois recursos extraordinários (n` 370682 e n 353657), decidindo sobre o direito ao creditamento de IPI em decorrência da aquisição insumos não-tributados, sujeitos a alíquota zero e ainda os isentos.

o Supremo Tribunal Federal declarou a impossibilidade de compensação de créditos de IPI nessas condições tributárias, ou seja, decidiu pela constitucionalidade da vedação do crédito do IPI nas hipóteses de alíquota zero.

Diante disso importante a fundamentação do M inistro Relator de tais processos, o qual teve o voto acolhido pela maioria:

\footnotetext{
"A equação segundo a qual a não-tributação e a alíquota zero viabilizam creditamento pela alíquota da operação final conflita com a letra do inciso II do §3은 do artigo 153 da Constituição Federal, que versa sobre a compensação do "montante cobrado nas anteriores", diga-se, nas operações anteriores. Não tendo sido cobrado nada, absolutamente nada, nada há a ser compensado, mesmo porque inexiste a alíquota que, incidindo, por exemplo, sobre o valor do insumo, revelaria a quantia a ser considerada.

Tomar por empréstimo a alíquota final atinente a operação diversa implica ato de criação normativa para o qual o Judiciário não conta com a indispensável competência." (STF, RE no. 353.657/PR voto relator Min. Marco Aurélio). (acórdão ainda não publicado)
}

A interpretação atribuída pelo M in. M arco Aurélio a expressão "montante cobrado nas anteriores" (art. 153, $\S 3^{\circ}$, da CF) demonstra-se notadamente literal, a qual não se apresente como mais indicada, principalmente em razão da mitigação que expressa ao princípio da seletividade, pois inviabilizará o incentivo ao consumo de determinado insumo em razão da minoração de sua carga tributária.

As razões do relator ainda se mostram contrárias ao princípio da nãocumulatividade, ao qual não foi dada qualquer restrição no caso específico do IPI pela Constituição Federal. De tal forma, tratado pelo legislador constitucional, evidentemente, de 
forma diversa do ICM(S), imposto que sofre restrições ao princípio da não-cumulatividade, restrições estas advindas de emenda constitucional.

A cerca da citada decisão, o professor Kiyoshi Harada exprime grande preocupação, pois segundo ele:

0 governo, que sempre esteve e está à procura de meios cada vez mais eficazes e fala-se até em ilegalidade eficaz, talvez para compensar a falta de eficiência no direcionamento dos gastos públicos, poderá utilizar-se, indevidamente, da faculdade de ZERAR as alíquotas do IPI com o objetivo de aumentar a arrecadação desse imposto, sem o concurso do Poder Legislativo.(2007, p. 01)

Para evitar tais abusos por parte do governo, o professor levanta duas hipóteses: “(...) ou se concede um crédito presumido, ou o valor do produto que teve a alíquota ZERADA deve ser abatido da base de cálculo do produto final, sob pena de afrontar o princípio da não-cumulatividade do IPI."(2007, p. 01)

$\mathrm{Na}$ análise do presente tema é relevante trazer os apontamentos destacados no voto (divergência) do Min. Lewandowski, para ele o direito ao crédito não depende de autorização do legislador infraconstitucional, "ao contrário, este direito decorre da própria constituição e do regime por ela adotado para o tributo em causa, cuja essência consiste na não-cumulatividade". Ele ainda afirma que "não há qualquer óbice constitucional para que os contribuintes possam valer-se dos créditos decorrentes da aquisição de matérias-primas cuja entrada isenta não tributada ou sobre a qual incide alíquota zero".

Para Lewandowski, o não creditamento implica em onerar toda a cadeia produtiva, o que não era a intenção do legislador.

Nota-se que o STF tomou a presente decisão em contrariedade do que se poderia esperar, pois existiam reiteradas decisões no sentido de ser devido o crédito decorrente de produtos isentos, como exemplo, tem-se os produzidos na Zona Franca de Manaus. E ainda, havia a idéia de que na prática os produtos isentos e os sujeitos à alíquota zero acabariam por gerar a mesma conseqüência, qual seja, a de não gerar a obrigação tributária.

Outro ponto que implicaria em expectativa de decisão diversa por parte do supremo e a questão da diferenciação do tratamento constitucional que receberam ICM (S) e $\mathrm{IPI}$, pois aquele primeiro teve a vedação expressa ao direito de creditamento. Diante disso poder-se-ia facilmente concluir que, se a intenção do legislador fosse dar aos dois impostos 
tratamentos idênticos teria sido expresso neste sentido, como não o fez, a conclusão oposta poderia ser tida como certa.

Da análise da decisão do supremo é relevante lembrar que, a ela foi dado efeito extunc, ou seja, aqueles contribuintes que já usaram o creditamento referente a tais insumos terão que pagar a diferença. E também, que até com relação aos insumos isentos não mais será permitido o cretidamento, ou seja, modificando o posicionamento de vários julgados anteriores do próprio STF.

\section{Conclusão}

Demonstrou-se com a presente análise que o IPI é um imposto com caráter não cumulativo, ou seja, o IPI pago em operações anteriores é abatido nas posteriores.

E ainda, que esse tem como um de seus princípios fundamentais o princípio da seletividade, que implica em aumentar ou diminuir a alíquota de produtos objeto do fisco de acordo com a sua essencialidade para o interesse social, tal princípio configurando-se como importante instrumento para a extrafiscalidade, que é o uso da tributação com fins não meramente arrecadatórios.

Foi analisada, ainda, a diferença de produtos isentos e produtos sujeitos à alíquota zero, onde os primeiros implicam em limitações à abrangência da regra matriz de incidência tributária, a qual se dá em virtude do ataque a pelo menos um de seus critérios, por meio de lei infraconstitucional. Lembrou-se que as isenções estão, normalmente, ligadas a fins de interesse nacional como auxiliar o desenvolvimento de determinada região.

Por sua vez, a sujeição às alíquotas zero não mitigam a atuação da regra de incidência tributária, se dá por meio de interesse do Poder Executivo, o qual pode alterar as alíquotas por meio de decretos. Tal prática tem por escopo incentivar, facilitar ou não incentivar a aquisição de determinados produtos.

Apurou-se que o direito a crédito de IPI em decorrência da aquisição de insumos sujeitos a alíquota zero, é um direito decorrente do próprio principio da não-cumulatividade, o qual, no caso do IPI, não sofre qualquer tipo de restrição constitucional, diferentemente do que acontece com o ICM(S). Reputou-se inconstitucional qualquer tipo de limitação, que não adviesse da própria Constituição Federal. 
Analisou-se, por fim, a atual posição do Supremo Tribunal Federal a cerca da problemática, a qual implica contrariedade da doutrina majoritária, pois vem adotando 0 entendimento de que é constitucional a vedação ao creditamento de IPI relativo a insumos não tributados, sujeitos a 'alíquota zero' e até mesmo os isentos.

Tal entendimento mostrou-se contrário ao entendimento anterior do próprio STF, no caso dos produtos isentos, e ainda poderá ensejar abusos por parte dos governos com a fim de majorarem a arrecadação tributária.

Este posicionamento do STF reflete-se claramente como uma decisão política, no sentido de proteger vultoso quinhão da arrecadação tributária federal, e não uma decisão jurídica, pois implica na imposição de limitação ao princípio da não-cumulatividade do IPI, situação a qual só se visualiza no caso do ICM em decorrência de previsão expressa da constituição.

\section{Referências}

BALEEIRO, Aliomar. Directo Tributário Brasileiro. 11. ed. atual. Rio de Janeiro: Forense, 2003.

BOTALHO, Eduardo domingos. Fundamentos do IPI. São Paulo: Revista dos Tribunais, 2002.

CARVALHO, M odesto. A ordem econômica na Constituição de 1969. São Paulo: RT, 1972.

CARVALHO, Paulo de Barros. Curso de Direito Tributário. ed. 18. rev. e atual. São Paulo: Saraiva, 2007.

HARADA, Kiyoshi. IPI. Perigo de quebra do princípio da não-cumulatividade . Jus Navigandi, Teresina, v. 11, n. 1576, 25 out. 2007. Disponível em:

বttp://jus2.uol.com.br/doutrina/texto.asp?id=10564>. Acesso em: 06 nov. 2007.

M ACHADO, Hugo de Brito. Comentários ao Código Tributário Nacional. São Paulo: Atlas, 2003. v. 1.

M ACHADO, Hugo de Brito. Crédito de IPI na Aquisição de Insumos não-tributados. Hugo Machado, Fortaleza, 2007. Disponível em:

\ttp:// www.hugomachado.adv.br/conteudo.asp?home $=1 \&$ secao $=2 \&$ situacao $=2 \&$ doc_id $=1$ 03>. Acesso em: 06 nov. 2007.

TORRES, David. Revelando o Sistema Tributário Brasileiro. São Paulo: Edições Sinafresp, 2003. 
TORRES, Ricardo Lobo. O IPI e o princípio da seletividade. Revista Dialética de Direito Tributário, São Paulo, n. 18, 1994.

STF. Jurisprudência. Brasília, 2007. Disponível em: «www.stf.gov.br>. 